\title{
Upper extremity motor quality evaluation in children with Cerebral Palsy
}

\author{
Avaliação da qualidade motora das extremidades \\ superiores de crianças com Paralisia Cerebral
}

\author{
Haryelle Náryma Confessor Ferreira, Gabriele Natane de Medeiros Cirne, Silvana Alves Pereira, \\ Núbia Maria Freire Vieira Lima, Roberta de Oliveira Cacho, Enio Walker Azevedo Cacho*
}

Faculdade de Ciências da Saúde do Trairi, Universidade Federal do Rio Grande do Norte (Facisa/UFRN), Santa Cruz, RN, Brazil

\begin{abstract}
Introduction: Cerebral Palsy (CP) is a non-progressive disorder that may compromise functional abilities of the upper limbs due to motor and sensitive loss, that are still poorly evaluated and described by reliable tools. Objective: This study aimed to evaluate motor quality and skills of the upper extremity in children with CP in regions of Trairi and Seridó from Rio Grande do Norte state (Brazil). Methods: It is a crosssectional exploratory study, with a qualitative approach, with 17 children with $\mathrm{CP}$, aged between four and eight years. The following instruments were used for upper extremity evaluation: Manual Ability Classification System (MACS), Quality of Upper Extremity Skills Test (QUEST) and Gross Motor Function Classification System (GMFCS). Results: Mean and standard deviation (sd) of QUEST total score and the domains dissociated movement, grasp, weight bearing and extensive protection were, respectively, 41.06/37.08; 53.12/34.50; 15.51/62.98; 37.76/37.52; 42.48/47.26. MACS and GMFCS median scores were, respectively, 3 (three) and 5 (five); high positive correlation was observed between MACS and
\end{abstract}

\footnotetext{
* HNCF: Master's Student, e-mail: haryelle_naryma@yahoo.com.br GNMC: Master's Student, e-mail: Gabriele_cirne@hotmail.com SAP: PhD, e-mail: apsilvana@gmail.com NMFVL: PhD, e-mail: nubiavl@yahoo.com.br ROC: PhD, e-mail: ro_fisio1@hotmail.com EWAC: PhD, e-mail: eniowalker@bol.com.br
} 
GMFCS (rs=0.83) and high negative correlation between GMFCS and total QUEST ( $\mathrm{rs}=-0.83$ ), as well as between MACS and QUEST (rs=-0.84); and MACS and all QUEST domains ( $\mathrm{rs}=-0.73$; rs=-0.82; rs=-0.76; rs $=-0.79$ ), $p<0.001$. Conclusion: Children with CP showed deficit in motor quality and skills of the upper limb, allowing to infer functional limitations regarding manipulation of objects and consequent dependence during life activities.

Keywords: Cerebral Palsy. Upper Extremity. Aptitude.

\section{Resumo}

Introdução: A Paralisia Cerebral (PC) é uma desordem não progressiva que pode comprometer as habilidades funcionais dos membros superiores, frequentemente decorrentes das perdas motoras e sensitivas, que são ainda pouco avaliadas e descritas por meio de instrumentos confiáveis. Objetivo: Este estudo teve como objetivo avaliar a qualidade de habilidades motoras e da extremidade superior em crianças com paralisia cerebral em regiões de Trairi e Seridó do estado do Rio Grande do Norte (Brasil). Métodos: Estudo exploratório, com abordagem qualitativa e estrutura transversal, com 17 crianças com PC, com idades entre quatro e oito anos. Foram utilizados os seguintes instrumentos para avaliação da extremidade superior: Sistema de Classificação da Habilidade Manual (MACS), Teste de Qualidade de Habilidades da Extremidade Superior (QUEST) e Sistema de Classificação da Função Motora Grossa (GMFCS). Resultados: A média e o desvio padrão da pontuação total QUEST e domínios dissociação de movimento, preensão, descarga de peso e resposta extensiva protetora foram, respectivamente, 41,06/37,08; 53,12/34,50; 15,51/62,98; 37,76/37,52; 42.48/47.26. As pontuações medianas do MACS e GMFCS foram, respectivamente, de 3 (três) a 5 (cinco), sendo observados alta correlação positiva entre MACS e GMFCS ( $r s=0,83$ ) e alta correlação negativa entre o GMFCS e QUEST totais ( $r s=-0,83)$, bem como entre MACS e QUEST (rs=-0,84); MACS e todos os domínios QUEST (rs=-0.73; rs=-0.82; rs=-0.76; $r s=-0.79), p<0,001$. Conclusão: As crianças com PC apresentaram déficit de qualidade motora e habilidades do membro superior, possibilitando inferir limitações funcionais quanto à manipulação de objetos e consequente dependência durante atividades de vida.

Palavras-chave: Paralisia Cerebral. Extremidade Superior. Aptidão.

\section{Introduction}

Cerebral Palsy (CP) has a heterogeneous character and it is defined as a non-progressive neurological condition caused due to injury in the immature brain that affects movements and posture. There are multiple etiologies involved, which result in Central Nervous System (CNS) injury [1].

Upper extremities of children with $\mathrm{CP}$ are generally impaired in skills such as reaching, grasping, transport, release and manipulation of objects, that decisively cause low quality achievement and performance of daily living activities [2]. Thus, basic ability to interact with people and to adapt to different environments is another factor that limits activity and participation. Motor disability in children with CP causes limitation in physical activity and in general experience $[3,4]$.
The importance of Upper Limbs (UL) movements to perform Activities of Daily Living (ADLs) is acknowledged by therapists working in motor function rehabilitation. Without arm movement, for the hand to reach the object and/or target, hand motor skills are restricted, precluding many reaching and grasping motor functions [5-7]. For example, the act of pushing a wheelchair is only possible after a coordinated action of several hand, arm and torso muscles. Such motor actions, no matter how elementary they are, when not performed, they might generate serious barriers in personal activities and social interactions $[8,9]$.

Some clinical in combination [10], are features such as associated with hand spasticity, dystonia, and arm movement choreoathetosis or disorders of children ataxia, that often occur with CP. Thus, there are 
few clinical instruments for assessment of motor function of upper extremities dissociated movement of children with CP. Other studies use complex tools, such as the kinematics to describe functional and motor impairment of the upper extremity of children with CP [8-11]. However, these instruments are not available for most therapists involved in upper extremity rehabilitation.

Studies show $[12,13]$ that children with CP have greater difficulty in releasing objects than reaching them, as well as to hold smaller objects, due to their limitation in fine movements $[14,15]$. Upperextremity disorders impair participation in daily life, therefore an adequate therapeutic planning is important to improve independence and integration on a day-to-day basis [16].

The evaluation process should be constant and make decisive contributions in planning therapeutic programs of widely different rehabilitation centers and in the use of valid, reliable and sensitive instruments, which generate useful information in determining care practices.

There are no studies that evaluate the upper extremity of children with $\mathrm{CP}$ in the northeastern region of Brazil. Thus, there is a need for information to identify which are the main motor changes and consequent functional limitations of children with $\mathrm{CP}$ in this region.

Therefore, identification of these quantitative characteristics may facilitate adoption of targets in order to provide purchasing of orthosis, wheelchairs and other relevant devices. It may also instigate inclusion of public policies that contribute to improve mobility, functionality and accessibility for this public.

In addition, a qualitative analysis is essential to determine a suitable physical therapy program, resulting in significant clinical improvement of these individuals. Thus, the aim of this study was to evaluate the motor quality and skills of the upper extremity in children with cerebral palsy attended in Trairi and Seridó regions in Rio Grande do Norte state (Brazil).

\section{Methods}

It is a cross-sectional exploratory study, with qualitative approach, developed at the school clinic of Physical Therapy of the College of Health
Sciences of Trairi (Facisa/UFRN), at the Children's Rehabilitation Center (CRI) of Santa Cruz/RN and at the Rehabilitation Center Professor Crindélia Bezerra (Currais Novos/RN).

Sample was allocated by convenience, according to the following criteria: age between four and eight years (according to instruments adequacy), both genders, clinically diagnosed with Cerebral Palsy (CP), who agreed to participate voluntarily in the study by responsible adults' signature, at legal age, in the Informed Consent Form. Children who presented other diseases associated with CP (cardiorespiratory and rheumatic diseases), as well as joint and skeletal muscle changes that compromised the passive range of motion of the upper limb movement were excluded from the study.

\section{Assessment Instruments}

Three assessment instruments were used:

1) Manual Ability Classification System (MACS): it assesses manual skills in people aged from four to 18 years. MACS describes five levels (from level I, ability to manipulate objects easily and successfully; to level $\mathrm{V}$, one does not manipulate objects and has severely limited ability to perform even simple actions), which are based on children's ability to start handling objects alone and the need for assistance or adaptation to perform manual activities in daily life. Information about relevant daily activities of objects manipulation was acquired by interviews with parents and/or guardians [17].

2) Quality of Upper Extremity Skills Test (QUEST) is a reliable and valid assessment tool that evaluates function quality of the upper limb in four areas: QUEST A dissociated movement (shoulder, elbow, wrist, fingers - 32 items); QUEST B - grasp (cube of $2.5 \mathrm{~cm}$, cereals, pencil or pen -12 items); QUEST C - protective extension (anterior, lateral, posterior - 18 items) and QUEST D - weight bearing (in prone, quadruped - 25 items) [18]. QUEST evaluates head, trunk and shoulders position during grasp movement, classifying them under normal or atypical. Scores were calculated for each subject by adding items that 
corresponded to them, assigning one point for every "yes" answer. Thus, total and each domain score may range from zero (worst performance) to 100 (best performance). Human hand grasping mechanisms depend on the object's characteristics, and a QUEST domain evaluates it through grasp tasks that replicate functional activities and verify hand motor skills [18]. Therefore, this domain demonstrates, by quantitative measures, great children inability to perform grasping of cubes, grains/beans and pencil/pen.

3) Gross Motor Function Classification System (GMFCS): it assesses abilities and limitations in child gross motor function and the need for manual devices for mobility on a fivelevel scale: Level I, the child walks without limitations; level II, the child walks with limitations; Level III, the child walks with a manual device mobility; Level IV, self-mobility with limitations, the child may use motorized mobility device; level $\mathrm{V}$, the child needs a manual wheelchair to move $[19,20]$.

Instruments administration

This study was developed after approval by the Ethics Committee of the Federal University of Rio Grande do Norte, following guidelines and recommendations of Resolution 466/12 on research on humans (730.810/2014).

Instruments applications were performed by two previously trained investigators. Both used manuals of each instrument as an aid. The average total time for the instruments applications was 30 minutes.

The following material was used: one (1) wooden cube of an inch; one (1) ballpoint pen; one (1) chair and one (1) wooden table; and recreational toys.

QUEST and MACS are not translated into Portuguese language, therefore they were used in English and the illustrated manual accompanying, autodidactic QUEST and MACS was consulted in case of doubt. GMFCS was used in the Portuguese version [21].

\section{Data analysis}

Scores were tabulated in Microsoft Excel ${ }^{\circledR}$ for data analysis, domains were calculated according to their respective weights, whenever suitable, and then software BioEstat 5.3 was used. Data were subjected to descriptive analysis (mean, standard deviation, variance and median) and correlation (Spearman correlation coefficient).

Correlation coefficient was interpreted according to Munro [22]. From 0.00 to 0.25: little or no correlation; from 0.26 to 0.49 : low correlation; from 0.50 to 0.69: moderate correlation; from 0.70 to 0.89 : high correlation; $0.90-1.00$ : very high correlation. Thus, the higher the $r$ value (Spearman), the stronger the correlation. If it is positive $(r>0)$, as the variable $x$ (abscissa) grows, so does y (ordinate). If the correlation is negative $(\mathrm{r}<0)$, as $\mathrm{x}$ grows, $\mathrm{y}$ decreases (on average).

\section{Results}

Seventeen children living in Trairi region (Santa Cruz) and Seridó (Currais Novos) of Rio Grande do Norte (Brazil) were evaluated. They were registered in rehabilitation centers of the two cities.

Age median was six years, and the levels five for GMFCS and three for MACS prevailed. Each QUEST domain was scored individually, with total QUEST (ranging from 0 to 100) expressed mostly by $<50$ values (Table 1 ).

The study showed high negative correlation between all instruments and their domains, except for MACS and GMFCS that presented high positive correlation, which ensures association between these research instruments (Table 2).

Table $\mathbf{1}$ - Sample characterization and assessment tools

\begin{tabular}{cccccccccc}
\hline Children & Genre & Age & GMFCS & MACS & QUEST A & QUEST B & QUEST C & QUEST D & QUEST total \\
\hline 1 & F & 5 & 1 & 2 & 96.87 & 96.29 & 100 & 100 & 98.29 \\
2 & M & 6 & 2 & 3 & 98.43 & 92.59 & 96 & 100 & 96.75 \\
3 & M & 6 & 1 & 3 & 96.87 & 66.66 & 98 & 100 & 90.38 \\
\hline
\end{tabular}


Table 1 - Sample characterization and assessment tools

(Conclusion)

\begin{tabular}{cccccccccc}
\hline Children & Genre & Age & GMFCS & MACS & QUEST A & QUEST B & QUEST C & QUEST D & QUEST total \\
\hline 4 & $\mathrm{~F}$ & 5 & 1 & 2 & 81.25 & 55.55 & 66 & 100 & 75.70 \\
5 & $\mathrm{M}$ & 6 & 1 & 2 & 93.75 & 55.55 & 68 & 83.33 & 75.15 \\
6 & $\mathrm{M}$ & 4 & 4 & 3 & 76.56 & 51.85 & 68 & 83.33 & 69.93 \\
7 & $\mathrm{~F}$ & 6 & 5 & 3 & 64.05 & 81.48 & 50 & 50 & 61.38 \\
8 & $\mathrm{M}$ & 8 & 2 & 3 & 54.68 & 14.81 & 24 & 100 & 48.37 \\
9 & $\mathrm{M}$ & 6 & 5 & 3 & 31.25 & 11.11 & 12 & 0 & 18.12 \\
10 & $\mathrm{~F}$ & 5 & 5 & 5 & 68.75 & -14.81 & 12 & 0 & 16.48 \\
11 & $\mathrm{~F}$ & 7 & 5 & 5 & 12.5 & 11.11 & 28 & 0 & 12.90 \\
12 & $\mathrm{M}$ & 8 & 5 & 5 & 34.37 & -7.40 & 12 & 5.55 & 11.13 \\
13 & $\mathrm{~F}$ & 7 & 5 & 5 & 43.75 & -7.40 & 8 & 0 & 11.08 \\
14 & $\mathrm{~F}$ & 7 & 5 & 5 & 28.12 & 7.40 & 0 & 0 & 8.88 \\
15 & $\mathrm{~F}$ & 6 & 5 & 4 & 21.87 & -11.11 & 0 & 0 & 3.587 \\
16 & $\mathrm{M}$ & 8 & 5 & 5 & 0 & -120 & 0 & 0 & 0 \\
17 & $\mathrm{M}$ & 8 & 5 & 5 & 0 & -120 & 0 & 0 & 0 \\
Median & - & 6 & 5 & 3 & - & - & - & - & - \\
Min/Max & - & $4 / 8$ & $1 / 5$ & $2 / 5$ & - & - & - & - & - \\
Average/dp & - & $6.35 / 1.22$ & - & - & $53.12 / 34.50$ & $15.51 / 62.98$ & $37.76 / 37.52$ & $42.48 / 47.26$ & $41.06 / 37.08$ \\
\hline
\end{tabular}

Note: $F=$ female; $M=$ male; $M i n=$ minimum; $M a x=$ maximum.

Table 2 - Spearman correlation between the scales used

\begin{tabular}{lcccccc}
\hline TOOLS & GMFCS & QUEST (A) & QUEST (B) & QUEST (C) & QUEST (D) & QUEST (T) \\
\hline MACS (rs) & 0.83 & -0.73 & -0.82 & -0.76 & -0.79 & -0.84 \\
GMFCS $(\mathrm{rs})$ & - & - & - & - & & -0.83 \\
\hline
\end{tabular}

Note: $\mathrm{p}$-valor $<0.001$

According to the results reported on the tables previously mentioned, we observe disorders in the movement quality and upper limb activities limitation, emphasized by a bigger impairment in grasp domain (QUEST B $=15.51$ ) and a lower impairment in dissociated movement domain (QUEST A = 53.12).

\section{Discussion}

Most children with $\mathrm{CP}$ evaluated in our study showed large function impairment of the arm and hand, confirming findings reported by Klingels et al. [23], that reaffirmed the development of such functions in children with $\mathrm{CP}$ are often impaired and they justify these shortcomings because of central nervous injury followed by motor and sensory changes.
According to Furuya [11], reaching trajectory shifts are well documented in subjects with moderate to severe cerebral stroke, when there is abnormal muscle coactivation in the paretic upper limb due to synergy impairment during abduction with external rotation of the shoulder, extension and elbow flexion, similar in cerebral palsy. In reaching and grasping activities, children with $\mathrm{CP}$ show more pronounced compensatory movements in proximal segments, with trunk movement to compensate the forearm pronation increase [16, 24, 25] and decreased shoulder range of motion, with lateral trunk compensation [12].

Considering that reaching when in sitting position is one of the main functional activities of children with $\mathrm{CP}$ and that inappropriate postural control $[26,27]$, normally seen in these children, may affect reaching and grasping movements, it 
seems essential that, in any instrument which aims to assess the upper limb, there must be an evaluation of head, trunk and its adjustment mechanisms. However, QUEST does not standardize the way which the child should be positioned for the test. Thus, the following procedure was determined for evaluation in this study: a $45-\mathrm{cm}$ chair with trunk support, no arms support and a table, allowing the child to perform the requested items according to his/her potential.

Still regarding postural control and reactive movements of the upper limb, our study assessed, through QUEST, the protective extension and weight bearing, and low scores in these two areas were found. It is explained by neuromotor deficits, present in this population, which results in inability to coordinate responses to the imbalance and the need to explore a wider support base [28].

In this study, MACS presented median III and only other three children showed MACS higher than median (level II). This MACS level is worrying, since according to Barroso et al. [29], children with CP who have the lowest MACS levels have significantly more deficiencies and limitations of unimanual and bimanual activities. Data above are different from those reported by Arner et al. [30], who conducted a study of 367 children with CP in Sweden, and only $36 \%$ of children were classified as level III or less in MACS, that is, they were not independent in manual tasks, even using two upper limbs.

Klingels et al. [23] conducted the first study that compared instruments that assess upper limb function: QUEST and the Melbourne Assessment, by statistical analysis of a homogeneous sample. In this study, Melbourne and QUEST showed high correlation between them, which explains the concurrent validity of scales. However, inspection of the instruments content indicates they measure different aspects of upper limb function. QUEST emphasizes each function level of the upper limb bilaterally including analysis of dissociated movement (domains). The Melbourne Assessment is a measurement tool based on activities according to the International Classification of Functioning, Disability and Health and it is more suitable to determine motor skills status (fine and functional) of a child unilaterally.

In this study, when comparing total QUEST score with each of its domains, it is observed that in the last domains, the value shown enables better understanding of the upper extremity in the population (Table 1), and it was also reported by Thorley et al. [31], in a previous study with 94 Australian children, that presented better details of the upper limb impairment in each evaluated domain than in the total QUEST score.

In arm and hand function assessment of children with CP, other methods are also used, such as hand dynamometer, used by Klingels et al. [23], to ascertain grasp strength. However, unilateral function analysis was not the aim of this study and possible cognitive deficits were observed in most affected children that would possibly hinder the implementation and use of dynamometer.

During QUEST application, a good convenience in handling the instrument has been disclosed, mainly due to manual graphics and the easily accessible materials (inch cube, pencil, A4 sheets, beans) and the rapid descriptive understanding regarding MACS and GMFCS levels. However, during the investigation, no studies that corroborate these findings were found. In addition, there was no pain and/or fatigue report during the time children were evaluated, that could affect the results, since, as described by Hirsh et al. [32], skeletal muscle changes may generate pain and fatigue in children with CP, compromising the evaluation process. Thus, the average time for evaluation was 30 minutes for the most compromised children and 20 minutes for the less compromised.

In addition, we suggest the importance of investigating the relationship among time, location and brain injury size with impaired function, ability and quality of the upper limb in children with $\mathrm{CP}$, besides performing objective measurements generated by kinematic analysis of arm and hand [33].

\section{Conclusion}

Deficit in motor quality and skills of upper limb was observed through high scores in MACS and GMFCS and low scores on QUEST in children with CP from Rio Grande do Norte, allowing to infer functional limitations regarding objects manipulation and consequent dependence during life activities. Besides, such instruments were highly correlated, supporting their concomitant use.

Therefore, planning appropriate treatment in order to improve upper limb function (arm, wrist, 
hand and fingers) and independence in life is necessary, and it should be based on a comprehensive and detailed assessment of the upper limb.

Thus, we suggest further studies to be developed in this area, translation and validation of QUEST manual into Portuguese in order to make it more accessible for health professionals, mainly physical therapists and/or occupational therapists in northeastern region of Brazil, where there are no studies describing upper limb impairment profile by trusted and reliable clinical tools. Therefore, more research in this area with larger samples in order to trace the existing profile is necessary.

\section{References}

1. Ustad T, Sorsdahl AB, Ljunggren AE. Effects of intensive physiotherapy in infants newly diagnosed with cerebral palsy. Pediatr Phys Ther. 2009;21(2):140-8.

2. Jaspers E, Desloovere K, Bruyninckx H, Klingels $\mathrm{K}$, Molenaers G, Aertbeliën E, et al. Three-dimensional upper limb movement characteristics in children with hemiplegic cerebral palsy and typically developing children. Res Dev Disabil. 2011;32(6):2283-94.

3. Michelsen SI, Flachs EM, Uldall P, Eriksen EL, McManus V, Parkes J, et al. Frequency of participation of 8-12-year-old children with cerebral palsy: a multicentre cross-sectional European study. Eur J Paediatr Neurol. 2009;13(2):165-77.

4. Byoung-Hee L, Yu-Mi K, Goo-CHurL J. Mediating effects of the ICF domain of function and the gross motor function measure on the ICF domains of activity, and participation in children with cerebral palsy. J Phys Ther Sci. 2015;27(10):3059-62.

5. van Vliet P, Pelton TA, Hollands KL, Carey L, Wing AM. Neuroscience findings on coordination of reaching to grasp an object: implications for research. Neurorehabil Neural Repair. 2013;27(7):622-35.

6. Arakaki VC, Cardoso MCC, Thinen NC, Imamura M, Battistella LR, Bernardo VM, et al. Paralisia cerebral - membros superiores: reabilitação. Projetos e Diretrizes - Associação Médica Brasileira. 2012. 18 p.
7. Schneiberg S, Consentino F. Função do Membro Superior em Crianças com Paralisia Cerebral e o Uso de Tarefas Direcionadas. In: Castilho-Weinert LV, FortiBellani CD, editors. Fisioterapia em Neuropediatria. Curitiba: Ominipax; 2011. p. 87-106.

8. Shikako-Thomas K, Majnemer A, Law M, Lach L. Determinants of participation in leisure activities in children and youth with cerebral palsy: systematic review. Phys Occup Ther Pediatr. 2008;28(2):155-69.

9. Wright FV, Rosenbaum PL, Goldsmith $\mathrm{CH}$, Law MM, Fehlings DL. How do changes in body functions and structures, activity, and participation relate in children with cerebral palsy? Dev Med Child Neurol. 2008;50(4):283-9.

10. Peng Q, Park HS, Shah P, Wilson N, Ren Y, Wu YN, et al. Quantitative evaluations of ankle spasticity and stiffness in neurological disorders using manual spasticity evaluator. J Rehabil Res Dev. 2011;48(4):473-81.

11. Furuya $M$, Ohata $K$, Izumi $K$, Matsubayashi J, Tominaga W, Mitani A. Effect of the angle of shoulder flexion on the reach trajectory of children with spastic cerebral palsy. Res Dev Disabil. 2014;36C:413-8.

12. Coluccini M, Maini ES, Martelloni C, Sgandurra G, Cioni G. Kinematic characterization of functional reach to grasp in normal and in motor disabled children. Gait Posture. 2007;25(4):493-501.

13. Eliasson AC, Gordon AM. Impaired force coordination during object release in children with hemiplegic cerebral palsy. Dev Med Child Neurol. 2000;42(4):228-34.

14. Chang JJ, Wu TI, Wu WL, Su F. Kinematical measure for spastic reaching in children with cerebral palsy. Clin Biomech (Bristol, Avon). 2005;20(4):381-8.

15. Visicato LP, Costa CSN, Damasceno VAM, Campos AC, Rocha NACF. Evaluation and characterization of manual reaching in children with cerebral palsy: A systematic review. Res Dev Disabil. 2014;36C:162-74.

16. Klotz MCM, van Drongelen S, Rettig O, Wenger P, Gantz S, Dreher T, et al. Motion analysis of the upper extremity in children with unilateral cerebral palsy - an assessment of six daily tasks. Res Dev Disabil. 2014;35(11):2950-7. 
17. Eliasson AC, Krumlinde-Sundholm L, Rösblad B, Beckung E, Arner M, Ohrvall AM, et al. The Manual Ability Classification System (MACS) for children with cerebral palsy: scale development and evidence of validity and reliability. Dev Med Child Neurol. 2006;48(7):549-54.

18. DeMatteo C, Law M, Russell D, Pollock N, Rosenbaum P, Walter S. QUEST: Quality of Upper Extremity Skills Test. Hamilton, ON: McMaster University, CanChild Centre for Childhood Disability Research; 1992. [cited 2015 Aug 12]. Available from: https://tinyurl.com/ ycm6ok6l.

19. Jooyeon K, Ji-Hea W, Jin-Gang H. The Reliability and Concurrent Validity of the GMFCS for Children with Cerebral Palsy. J Phys Ther Sci. 2011;23(2): 255-8.

20. Palisano RJ, Rosenbaum P, Bartlett D, Livingston MH. Gross motor function classification system: expanded and revised (GMFS- F\&R). 2007 [cited 2015 Nov 30]. Available from: https://tinyurl.com/ya6y7gzl.

21. Hiratuka E, Matsukura TS, Pfeifer LI. Cross-cultural adaptation of the Gross Motor Function Classification System into Brazilian-Portuguese (GMFCS). Rev Bras Fisioter. 2010;14(6):537-44

22. Munro BH. Statistical Methods for Health Care Research. 5th ed. Philadelphia: Lippincott Williams \& Wilkins; 2004.

23. Klingels $\mathrm{K}$, De Cock $\mathrm{P}$, Desloovere $\mathrm{K}$, Huenaerts $\mathrm{C}$, Molenaers G, Van Nuland I, et al. Comparison of the Melbourne Assessment of Unilateral Upper Limb Function and the Quality of Upper Extremity Skills Test in hemiplegic CP. Dev Med Child Neurol. 2008;50(12):904-9.

24. Rönnqvist L, Rösblad B. Kinematic analysis of unimanual reaching and grasping movements in children with hemiplegic cerebral palsy. Clin Biomech (Bristol, Avon). 2007;22(2):165-75.

25. Mackey AH, Walt SE, Stott NS. Deficits in upper-limb task performance in children with hemiplegic cerebral palsy as defined by 3-dimensional kinematics. Arch Phys Med Rehabil. 2006;87(2):207-15.
26. Ansuini C, Santello M, Massaccesi S, Castiello U. Effects of end-goal on hand shaping. J Neurophysiol. 2006;95(4):2456-65.

27. Ju YH, Hwang IS, Cherng RJ. Postural Adjustment of children With Spastic Diplegic Cerebral Palsy During Seated Hand Reaching in Different Directions. Arch Phys Med Rehabil. 2012;93(3):471-9.

28. Pavão SL, Nunes GS, Santos AN, Rocha NACF. Relação entre o controle postural estático e o nível de habilidades funcionais na paralisia cerebral. Braz J Phys Ther. 2014;18(4):300-7.

29. Barroso PN, Vecchio SSD, Xavier YR, Sesselmann M, Araújo PA, Pinotti P. Improvement of hand function in children with cerebral palsy via an orthosis that provides wrist extension and thumb abduction. Clin Biomech (Bristol, Avon). 2011;26(9):937-43.

30. Arner M, Eliasson AC, Nicklasson S, Sommerstein $\mathrm{K}$, Hägglund G. Hand function in cerebral palsy, report of 367 children in a population based longitudinal heath care program. J Hand Surg Am. 2008;33(8):1337-47.

31. Thorley M, Lannin N, Cusick A, Novak I, Boyd R. Construct validity of the Quality of Upper Extremity Skills Test for children with cerebral palsy. Dev Med Child Neurol. 2012;54(11):1037-43.

32. Hirsh AT, Gallegos JC, Gertz KJ, Engel JM, Jensen MP. Symptom burden in individuals with cerebral palsy. J Rehabil Res Dev. 2010;47(9):863-76.

33. Klingels K, Demeyere I, Jaspers E, De Cock P, Molenaers G, Boyd R, et al. Upper limb impairments andtheir impact on activity measures in children with unilateral cerebral palsy. Eur J Paediatr Neurol. 2012;16(5):475- 84.

Received on $03 / 20 / 2016$

Recebido em 20/03/2016

Approved on 09/18/2017

Aprovado em 18/09/2017 